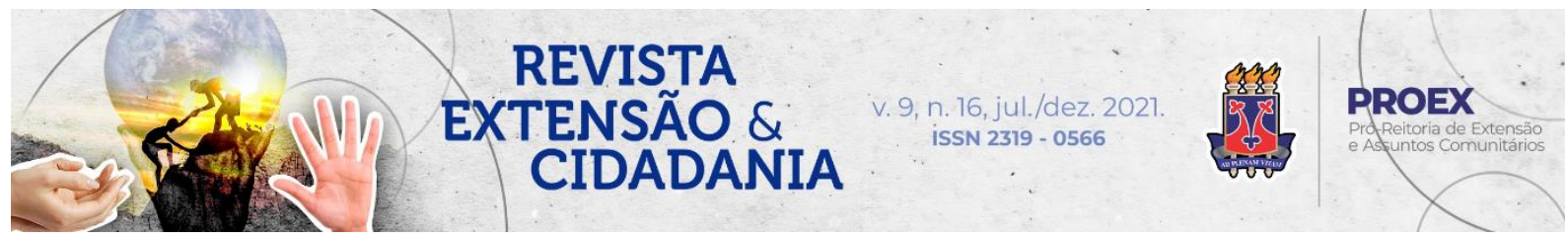

DOI: $10.22481 /$ recuesb.v9i16.9828

\title{
AVALIAÇÃO DA QUALIDADE DAS ÁGUAS DE DIFERENTES FONTANÁRIOS PÚBLICOS DE POÇOS DE CALDAS, ESTADO DE MINAS GERAIS, BRASIL
}

\author{
EVALUATION OF THE QUALITY OF WATER FROM DIFFERENT PUBLIC \\ FOUNTAINS IN POÇOS DE CALDAS, MINAS GERAIS STATE, BRAZIL \\ EVALUACIÓN DE LA CALIDAD DEL AGUA DE DIFERENTES FUENTES \\ PÚBLICAS EN POCGOS DE CALDAS, ESTADO DE MINAS GERAIS, BRAZIL
}

\author{
Juliana Carvalho Ribeiro ${ }^{1}$ \\ Maria de Fátima Lino Coelho ${ }^{2}$ \\ Yula de Lima Merola ${ }^{3}$
}

\begin{abstract}
Resumo: Poços de Caldas é uma cidade brasileira, localizada no Sul do estado de Minas Gerais, que se destaca em função da presença de diversos fontanários hidrominerais. Em função do grande consumo e da falta de cuidados básicos de higiene por parte de muitos usuários, questiona-se quanto à possível contaminação da água nesses locais, pode causar doenças de veiculação hídrica. $\mathrm{O}$ objetivo deste trabalho foi realizar um projeto de extensão abordando análises físico-químicas, microbiológicas e parasitológicas de amostras de água coletadas em seis fontanários públicos de diferentes regiões da cidade. Para as análises físico-químicas foram avaliadas as características organolépticas, $\mathrm{pH}$ e testes colorimétricos qualitativos para sulfato, cloreto, amônio, cálcio e magnésio. As análises microbiológicas realizadas foram análise de bactérias viáveis e presença de Escherichia coli. De acordo com as análises parasitológicas e físico-químicas, as amostras atenderam aos padrões de potabilidade. Porém, em duas amostras observou-se valores de $\mathrm{pH}$ levemente alcalinos. As análises microbiológicas atenderam aos padrões de potabilidade e em uma amostra observou-se estado de alerta em função da presença de unidades formadoras de colônia de bactérias viáveis. Conclui-se que 66,7\% das amostras atenderam os padrões de potabilidade, porém as amostras 2 e 5 (33,3\% das amostras) foram reprovadas por apresentarem valores de $\mathrm{pH}$ acima do indicado. Recomenda-se um
\end{abstract}

\footnotetext{
1 Farmacêutica; Doutora em Toxicologia, pela Faculdade de Ciências Farmacêuticas de Ribeirão Preto, Universidade de São Paulo (FCRP-USP). Professora substituta no curso de Farmácia na Universidade Federal de Alfenas (UNIFAL), Alfenas, Minas Gerais, Brasil. Orcid: http://orcid.org/0000-0003-3724-2321 E-mail: rbrjuliana@yahoo.com.br

${ }^{2}$ Farmacêutica; Mestre em Ciências Médicas, área de concentração Patologia Clínica, pela Universidade Estadual de Campinas (UNICAMP). Professora do curso de Farmácia na Faculdade Pitágoras de Poços de Caldas, Minas Gerais, Brasil. Orcid: http://orcid.org/0000-0002-7961-7120Ｅ-mail: mfl.coelho@yahoo.com.br

${ }^{3}$ Farmacêutica; Doutora em Ciências da Saúde, pela Faculdade de Ciências Médicas da Universidade de Campinas (UNICAMP). Professora do curso de Farmácia na Faculdade Pitágoras de Poços de Caldas, Minas Gerais, Brasil. Orcid: https://orcid.org/0000-0003-3576-9365 E-mail: yulamerola7@gmail.com
} 
monitoramento continuado e frequente da potabilidade da água para maior segurança dos usuários e direcionando ações corretivas futuras.

Palavras-chave: Potabilidade da água. Água mineral. Poços de Caldas. Fontanários hidrominerais. Análise de água.

Abstract: Poços de Caldas is a Brazilian city, located in the south of Minas Gerais, stands out due to the presence of several hydromineral fountains. The high consumption and the lack of basic hygiene precautions by many users, raise questions about the possible water contamination in these places, which may cause waterborne diseases. The objective of this work was to carry out physicochemical, microbiological and parasitological analyzes of water samples collected from six public fountains in different regions of the city. For the physicochemical analyzes, the organoleptic characteristics, $p H$ and qualitative colorimetric tests for sulfate, chloride, ammonium, calcium and magnesium were evaluated. The microbiological analyzes performed were analysis of viable bacteria and the presence of Escherichia coli. Parasitological analyzes were performed using the spontaneous sedimentation method. The samples met the potability standards according to the for parasitological and physical-chemical analyzes. However, in two samples a slightly alkaline pH value was observed. The microbiological analyzes met the standards and in one sample, a state of alert was observed due to the presence of colony-forming units of viable bacteria. In conclusion, the results show four samples met the potability standards, however, samples 2 and 5 were disapproved for presenting $\mathrm{pH}$ values above that indicated. Continued and frequent monitoring of water potability is recommended for greater safety for users and directing future corrective actions.

Keywords: Water potability. Mineral water. Poços de Caldas. Hydromineral fountains. Water analysis.

Resumen: Poços de Caldas es una ciudad brasileña, ubicada al sur del estado de Minas Gerais, que se destaca por la presencia de fuentes hidrominerales. Debido al alto consumo y la falta de cuidados básicos de higiene por parte de muchos usuarios, surgen interrogantes sobre la posible contaminación del agua en estos lugares, que puede provocar enfermedades de transmisión hídrica. El objetivo de este trabajo fue llevar a cabo un proyecto de extensión que aborde los análisis físico-químicos, microbiológicos y parasitológicos de muestras de agua recolectadas de seis fuentes públicas en diferentes regiones de la ciudad. Para los análisis fisicoquímicos se evaluaron características organolépticas, pH y pruebas colorimétricas cualitativas para sulfato, cloruro, amonio, calcio y magnesio. Los análisis microbiológicos realizados fueron análisis de bacterias viables y presencia de Escherichia coli. De acuerdo con los análisis parasitológicos y fisicoquímicos, las muestras cumplieron con los estándares de potabilidad. Sin embargo, en dos muestras, se observaron valores de pH ligeramente alcalinos. Los análisis microbiológicos cumplieron con los estándares de potabilidad y en una muestra hubo un estado de alerta debido a la presencia de unidades formadoras de colonias de bacterias viables. Se concluye que el 66,7\% de las muestras cumplieron con los estándares de potabilidad, pero las muestras 2 y 5 (33,3\% de las muestras) fueron desaprobadas por presentar valores de $\mathrm{pH}$ superiores a los indicados. Se recomienda un monitoreo continuo y frecuente de la potabilidad del agua para mayor seguridad de los usuarios y orientar futuras acciones correctivas.

Palabras clave: Potabilidad del agua. Agua mineral. Poços de Caldas. Fuentes hidrominerales. Análisis de agua.

Revista Extensão \& Cidadania, v. 9, n. 16, p. 21-32, jul./dez. 2021.

ISSN 2319-0566 DOI: 10.22481/recuesb.v9i16.9828 


\section{Introdução}

Poços de Caldas é uma cidade brasileira, localizada no sul do estado de Minas Gerais, segundo os dados da Prefeitura Municipal, o município situa-se num planalto elíptico, rodeado de montanhas com altitudes entre $1600 \mathrm{~m}$ e $1800 \mathrm{~m}$. O solo tem características geológicas diversas, sendo formado por extensa intrusão de rochas alcalinas denominadas sienitos nefelínicos, circundados por formações arqueanas. Esta região é marcada pela presença de grandes reservas de minérios ferrosos, não ferrosos e radiativos, o clima de Poços é caracterizado por invernos secos e verões brandos. A vegetação característica é a floresta tropical pouco densa, permitindo a fácil penetração de luz solar, favorecendo o aparecimento de vegetação arbustiva e herbácea (PREFEITURA MUNICIPAL DE POÇOS DE CALDAS, 2021).

Neste cenário, brotam águas naturais por toda a Serra de São Domingos e esta particularidade faz de Poços de Caldas uma cidade referência no uso de águas minerais, com destaque mundial. As águas minerais são também denominadas minero-medicinais, medicinais e termais. Ao longo da história, relata-se que as águas minerais foram batizadas como diamante líquido, petróleo, ouro, remédio universal, quer por suas virtudes terapêuticas, quer pelo potencial econômico que representam para um país e/ou uma região. Os lugares que circundam essas fontes foram denominados laboratórios da natureza ou farmácias da natureza. A partir delas, formaram-se ciências como a hidrologia, a hidrologia médica, a crenologia e, em torno destas, originaram-se disputas pela legitimidade de suas práticas, apoiadas em saberes populares ou empíricos, para outros, científicos (QUINTELA, 2004).

Em função da grande quantidade de minas de águas minerais, o distrito que deu origem ao município de Poços de Caldas foi, inicialmente, denominado Nossa Senhora da Saúde das Águas de Caldas. A popularização do uso das águas minerais de Poços de Caldas se confunde com a chegada da Ramal Mogiana de estradas de Ferro, no final do século XIX, pois, com a implantação da ferrovia, nasceu a história do turismo local, que teve seu auge nos meados do século XX, marcado pela construção de um cassino, um hotel e um balneário, este construído para tratamentos de saúde e que acabou levando o nome de Poços de Caldas para todo o mundo (MEGALE, 2002; MARRICHI, 2009). Nesta época, destacou-se também a construção de diversos fontanários públicos ao longo da cidade, facilitando o acesso à água por parte da população local e também dos turistas. A construção destas estruturas resultou em

Revista Extensão \& Cidadania, v. 9, n. 16, p. 21-32, jul./dez. 2021.

ISSN 2319-0566 DOI: 10.22481/recuesb.v9i16.9828 
desenvolvimento turístico, trazendo para Poços de Caldas pessoas vindas de longe, e na construção de residências de veraneio, elevando o status da estância hidrotermal (PREFEITURA MUNICIPAL DE POÇOS DE CALDAS, 2021). Porém, o fechamento dos cassinos em 1946 e a evolução dos medicamentos industrializados impactaram o turismo termal. A economia se recuperou da crise através das mineradoras, da chegada de indústrias e principalmente da mudança de foco na área turística (PREFEITURA MUNICIPAL DE POÇOS DE CALDAS, 2021).

No Brasil, a partir de 2006, despertou-se um novo olhar sobre o uso das águas minerais em tratamentos medicinais, desta vez reconhecida como uma Prática Integrativa e Complementar em Saúde (PICS) (BARBOSA; GUIMARÃES; SANTOS; BEZERRA; TESSER; SOUSA, 2020). Classificada como hidrologia médica, termalismo social ou crioterapia, o uso de água mineral e das demais PICS foi institucionalizado no Sistema Único de Saúde (SUS) pela Política Nacional de Práticas Integrativas e Complementares (PNPIC), aprovado pela Portaria $n^{\circ}$ 971, de 5 de março de 2006 (BRASIL, 2006). A finalidade de tal política do Ministério da Saúde é oferecer à população acesso às PICS, padronizando-a para atender às demandas da rede pública de saúde e apresentar-se em todos os níveis de atenção à saúde, disponibilizando à população diversas modalidades de tratamentos que não substituem os tratamentos convencionais, mas que trazem um importante reequilíbrio físico, mental e emocional, com foco na qualidade de vida do paciente (ANTUNES; DAHER; GIARETTA; FERRARI, 2019).

Porém, mesmo com essa retomada no uso terapêutico de águas minerais, é importante ressaltar que a qualidade das águas é um fator muito importante a ser considerado, pois as doenças de veiculação hídrica são um sério problema de saúde pública. As águas podem ser contaminadas por substâncias químicas, microrganismos e parasitas. As autoras Paiva e Souza (2018) relatam que cólera, febre tifóide e paratifoide, shiguelose, amebíase, diarreia e gastroenterite de origem infecciosa presumível, esquistossomose e outras doenças infecciosas intestinais foram responsáveis por 2,35\% das internações totais no Brasil, gerando uma parcela de $0,7 \%$ dos gastos totais do SUS e, afetando principalmente pessoas com 10 anos ou mais de idade.

O propósito primário para a exigência de qualidade da água é a proteção à saúde pública e os critérios adotados para assegurar essa qualidade têm por objetivo fornecer uma base para o desenvolvimento de ações que, se propriamente implementadas junto à população, garantirão

Revista Extensão \& Cidadania, v. 9, n. 16, p. 21-32, jul./dez. 2021.

ISSN 2319-0566 DOI: 10.22481/recuesb.v9i16.9828 
a segurança do fornecimento de água através da eliminação ou redução à concentração mínima de constituintes na água conhecidos por serem perigosos à saúde (DAHI, 1992). Quase invariavelmente, o melhor método de assegurar água adequada para consumo consiste em formas de proteção, evitando-se contaminações de dejetos animais e humanos, os quais podem conter grande variedade de bactérias, vírus, protozoários e helmintos. Falhas na proteção e no tratamento efetivo expõem a comunidade a riscos de doenças intestinais e a outras doenças infecciosas (BROMBERG, 1995; HELLER, 1998).

Sendo Poços de Caldas um município privilegiado pela presença de muitas minas de águas minerais, a avaliação da potabilidade da água é um parâmetro essencial para a garantia de acesso à água de boa qualidade. Assim, o Departamento Municipal de Água e Esgoto realiza e divulga periodicamente análises dos principais fontanários existentes na cidade. No entanto, em função da ampla quantidade de fontanários e minas, alguns não são monitorados e algumas pessoas têm a falsa ideia de que a água de origem natural não faz mal e pode ser consumida sem restrições (DMAE, 2021). Ainda, observa-se que se implantou na população local o hábito de frequentar e buscar águas nos diversos fontanários da cidade.

Existe uma prática frequente na população poços-caldense de utilização para consumo humano da água de fontanários não ligados a redes de distribuição públicas. Esta prática está de tal forma enraizada que, mesmo nos casos em que as populações são servidas por redes de distribuição pública, algumas preferem consumir a água deste tipo de fontanários, utilizando como argumento a sua gratuidade, o sabor menos agradável da água da rede, a ideia de que a água que a entidade gestora distribui não tem qualidade para ser ingerida ou até eventuais propriedades terapêuticas das águas dos fontanários.

Em função do grande consumo e da falta de cuidados básicos de higiene por parte de muitos usuários, questiona-se quanto à possível contaminação nesses locais, podendo causar doenças de veiculação hídrica. Neste sentido, o objetivo deste trabalho foi realizar análises físico-químicas, parasitológicas e microbiológicas de amostras de água coletada em fontanários públicos de diferentes regiões da cidade de Poços de Caldas, de forma a evidenciar os padrões de potabilidade de suas águas.

Revista Extensão \& Cidadania, v. 9, n. 16, p. 21-32, jul./dez. 2021.

ISSN 2319-0566 DOI: 10.22481/recuesb.v9i16.9828 


\section{Metodologia}

Este estudo é o resultado de um projeto de extensão do curso de Farmácia da Faculdade Pitágoras, de Poços de Caldas, Minas Gerais. Por meio de entrevista, seis alunos foram selecionados para a execução de análises laboratoriais, com o objetivo de evidenciar os padrões de potabilidade da água. Foram escolhidos seis fontanários, localizados em diferentes regiões da cidade, a fim de proporcionar boas práticas de análises em laboratório, elaborou-se quatro procedimentos operacionais padrões, sendo denominados (1) normas para amostragem de água potável; (2) análises físico-químicas; (3) análises microbiológicas e (4) análises parasitológicas da água potável. Para a execução do trabalho foram realizadas coletas de amostras d'água na saída dos fontanários e a amostragem seguiu os padrões da Portaria MS nº 518, de 25 de maio de 2004, da Fundação Nacional da Saúde (FUNASA).

A Portaria $n^{\circ}$ 2.914, de 12 de dezembro de 2011, do Ministério da Saúde (BRASIL, 2011) estabelece procedimentos e responsabilidades para o controle e vigilância da qualidade da água para consumo humano e seu padrão de potabilidade. Neste estudo, os procedimentos operacionais foram padronizados tendo como referência esta portaria e as técnicas descritas na Farmacopeia Brasileira (BRASIL, 2019). Esta referência bibliográfica aborda a monografia da água potável e também padroniza os métodos de análise, o que facilitou a elaboração dos procedimentos operacionais padrão.

As normas de coleta de água potável possibilitaram uma preparação correta e padronizada dos frascos e técnicas específicas de coleta para as diferentes análises. Os frascos de coleta foram padronizados em frasco vidro âmbar, com tampa, rotulados quanto ao tipo de análise e data de coleta. Os frascos foram higienizados com água e detergente neutro e secos em estufa de secagem. Usou-se o mesmo frasco para as análises microbiológicas e parasitológicas. Para estas análises, estes frascos depois de secos, receberam 0,5 g de tiossulfato de sódio P.A. para a neutralização de cloro, foram embalados, autoclavados e secos em estufa de secagem, garantindo um ambiente estéril para conter a amostra. Durante a coleta, foram tomados cuidados de modo a evitar a contaminação da amostra, isentas de detritos, folhas ou outro tipo de material acidental, imediatamente após a coleta, as amostras foram acondicionadas e levadas para análise. As análises microbiológicas e parasitológicas foram priorizadas e realizadas em câmara de fluxo laminar, as amostras das análises físico-químicas foram mantidas

Revista Extensão \& Cidadania, v. 9, n. 16, p. 21-32, jul./dez. 2021.

ISSN 2319-0566 DOI: 10.22481/recuesb.v9i16.9828 
sob refrigeração de 2 a $8^{\circ} \mathrm{C}$ até o momento da análise que não ultrapassou 24 horas após a amostragem.

Os procedimentos operacionais foram padronizados e elaborados mediante consulta na monografia para água potável descrita na Farmacopeia Brasileira (BRASIL, 2019). Para as análises físico-químicas foram avaliadas características organolépticas, $\mathrm{pH}$ e testes colorimétricos qualitativos para sulfato, cloreto, amônio, cálcio e magnésio.

As análises microbiológicas realizadas foram análise de bactérias viáveis e presença de Escherichia coli pela pesquisa de patógenos específicos. A análise de bactérias viáveis foi realizada pela contagem microbiana em meio sólido, usando o ágar triptona soja como meio de cultura. Inoculou-se $1 \mathrm{ml}$ da amostra de água em uma placa e $0,1 \mathrm{ml}$ em outra, em duplicata e as placas foram preenchidas com cerca de $20 \mathrm{ml}$ do meio de cultura líquido, homogeneizando pelo método Pour Plate. As placas foram levadas para estufa bacteriológica por 48 horas a $37^{\circ} \mathrm{C}$. Após este período, realizou-se a contagem das colônias, na placa em que foi colocado $0,1 \mathrm{ml}$ de amostra, o resultado foi multiplicado por 10 e como foram feitas 4 placas, o número total de colônias encontrado foi dividido por 4. Para a análise de Escherichia coli, colocou-se $5 \mathrm{ml}$ da amostra de água e $50 \mathrm{ml}$ de caldo BHI, levando-se para estufa bacteriológica por 24 horas a $37^{\circ} \mathrm{C}$. Após este período, realizou-se a pesquisa de patógenos específicos, descrita na Farmacopeia Brasileira, pelo método da semeadura em placa de ágar Mac Conkey, cujo resultado foi observado após 24 horas (BRASIL, 2019).

As análises parasitológicas foram realizadas pelo método da sedimentação espontânea por 24 horas, com posterior análise microscópica.

\section{Resultados e discussão}

Na Tabela 1 estão descritos os resultados das análises físico-químicas, microbiológicas e parasitológicas nos seis fontanários em análise.

Revista Extensão \& Cidadania, v. 9, n. 16, p. 21-32, jul./dez. 2021.

ISSN 2319-0566 DOI: 10.22481/recuesb.v9i16.9828 
Tabela 1 - Resultado das análises físico-químicas, microbiológicas e parasitológicas de seis fontanários de diferentes regiões na cidade de Poços de Caldas, Minas Gerais,

Brasil, 2019

\begin{tabular}{|c|c|c|c|c|c|c|c|}
\hline \multirow{2}{*}{$\begin{array}{l}\text { Análises físico- } \\
\text { químicas }\end{array}$} & \multirow{2}{*}{ Especificações } & \multicolumn{6}{|c|}{ Fontanários } \\
\hline & & 1 & 2 & 3 & 4 & 5 & 6 \\
\hline Aspecto & Líquido límpido e incolor & $\mathrm{C}$ & $\mathrm{C}$ & $\mathrm{C}$ & $\mathrm{C}$ & $\mathrm{C}$ & $\mathrm{C}$ \\
\hline Odor & Inodoro & $\mathrm{C}$ & $\mathrm{C}$ & $\mathrm{C}$ & $\mathrm{C}$ & $\mathrm{C}$ & $\mathrm{C}$ \\
\hline $\mathrm{pH}$ & Entre 6,0 e 9,5 & 9,10 & 11,05 & 8,99 & 8,67 & 11,01 & 8,88 \\
\hline Cloreto & Máximo 250mg/L & $\mathrm{C}$ & $\mathrm{C}$ & $\mathrm{C}$ & $\mathrm{C}$ & $\mathrm{C}$ & $\mathrm{C}$ \\
\hline Sulfato & Não ocorre alteração & $\mathrm{C}$ & $\mathrm{C}$ & $\mathrm{C}$ & $\mathrm{C}$ & $\mathrm{C}$ & $\mathrm{C}$ \\
\hline Amônio & Não ocorre alteração & $\mathrm{C}$ & $\mathrm{C}$ & $\mathrm{C}$ & $\mathrm{C}$ & $\mathrm{C}$ & $\mathrm{C}$ \\
\hline $\begin{array}{l}\text { Cálcio e } \\
\text { Magnésio }\end{array}$ & $\begin{array}{l}\text { Produz-se coloração azul } \\
\text { puro }\end{array}$ & $\mathrm{C}$ & $\mathrm{C}$ & $\mathrm{C}$ & $\mathrm{C}$ & $\mathrm{C}$ & $\mathrm{C}$ \\
\hline \multicolumn{8}{|c|}{ Análises microbiológicas } \\
\hline Bactérias viáveis & Até 100 UFC & 5 & 14 & 95 & 12 & 5 & 89 \\
\hline Escherichia coli & Ausente & $\mathrm{C}$ & $\mathrm{C}$ & $\mathrm{C}$ & $\mathrm{C}$ & $\mathrm{C}$ & $\mathrm{C}$ \\
\hline \multicolumn{8}{|c|}{ Análises parasitológicas } \\
\hline $\begin{array}{l}\text { Depósitos de ovos } \\
\text { e parasitas }\end{array}$ & Ausente & $\mathrm{C}$ & $\mathrm{C}$ & $\mathrm{C}$ & $\mathrm{C}$ & $\mathrm{C}$ & $\mathrm{C}$ \\
\hline
\end{tabular}

UFC: Unidade formadora de colônia; C: em conformidade; NC: Não conformidade

Fonte: Elaborado pelas autoras.

Nas análises físico-químicas observa-se valores em conformidade com os padrões especificados para as características organolépticas de aspecto e odor e para os testes qualitativos para cloreto, sulfato, amônio, cálcio e magnésio. Porém, ao analisar o pH, nota-se que os fontanários 2 e 5 demonstraram valores de $\mathrm{pH}$ acima do $\mathrm{pH}$ especificado. Esta característica alcalina pode estar relacionada com as características do solo da região, pois o Maciço de Poços de Caldas, segundo Garda (1990), destaca-se como uma das maiores manifestações de rochas alcalinas do mundo e faz parte do conjunto de intrusões alcalinas do Brasil Meridional. Na literatura consultada não foram encontradas referências mais recentes, evidenciando as características qualitativas e quantitativas do solo local para fins de comparação.

Nas análises microbiológicas, observou-se conformidade com os padrões estabelecidos. A ausência de Escherichia coli é um importante parâmetro a ser avaliado, pois esta bactéria cujo habitat é o intestino de mamíferos é um importante indicativo de contaminação fecal, o que pode estar relacionado com contaminações de microrganismos e parasitas. Em um estudo semelhante, Cavalcante (2014) observou altos índices de E. coli em fontes de água e pontos de consumo em uma comunidade rural de Alagoas, sendo recomendado intervenções adicionais visando a segurança desta população.

Revista Extensão \& Cidadania, v. 9, n. 16, p. 21-32, jul./dez. 2021.

ISSN 2319-0566 DOI: 10.22481/recuesb.v9i16.9828 
As bactérias viáveis, também chamadas heterotróficas, estão relacionadas com monitorização de bactérias ambientais. Os autores Domingues, Tavares, Stuker, Michelot, Reetz, Bertoncheli e Horner (2007) relatam que a contagem de bactérias heterotróficas é amplamente utilizada como indicador da qualidade da água potável, sendo que os microrganismos são detectados por propagação em meios não-seletivos. Nos fontanários 3 e 6 , observou-se estado de alerta em função da presença de unidades formadoras de colônia de bactérias viáveis bem próximos aos limites especificados, o que determina cautela. Sugere-se a reamostragem e o monitoramento continuado e frequente da potabilidade da água para maior segurança dos usuários destes dois fontanários. É importante ressaltar que este estudo não avaliou o índice de coliformes fecais, pois muitos fontanários são avaliados periodicamente neste parâmetro pelo Departamento Municipal de Água e Esgoto e optou-se então por análises de parâmetros diferentes dos parâmetros de análise de rotina, a fim de comparação dos resultados e detecção de limites de alerta.

Em função dos resultados encontrados, observa-se que 66,7\% das amostras analisadas estão de acordo com os padrões de potabilidade especificados, uma vez que em dois fontanários, o 2 e o 5 , os valores de $\mathrm{pH}$ detectados estão acima das especificações. A análise proposta usando parâmetros físico-químicos, microbiológicos e parasitológicos para determinar a potabilidade de água é um estudo pioneiro na região de Poços de Caldas. Na literatura consultada não foram encontrados estudos semelhantes realizados nesta região para fins de comparação. O estudo semelhante mais próximo encontrado na literatura é o de Silva; Maciel; Marta; Bronharo; Michelin (2018) que avaliou a qualidade da água de escolas públicas municipais na região de Araçatuba, do estado de São Paulo, pela análise microbiológica de Escherichia coli e coliformes fecais e análise físico-química de teor de nitrato. Os resultados foram preocupantes, apontando a necessidade de implantação de medidas de saneamento nas escolas avaliadas.

É importante ressaltar que esta análise foi realizada antes da pandemia de Covid-19. Para implantar medidas de segurança, o Departamento Municipal de Água e Esgoto instalou recipientes contendo álcool em gel 70\% e toalhas descartáveis de papel nos fontanários de maior público e também foram realizadas atividades de educação em saúde. Considerando que as bactérias viáveis são sensíveis ao álcool 70\%, acredita-se que os valores próximos aos limites de alerta encontrados em dois fontanários possam ter diminuído. Este é mais um motivo que reforça a reamostragem proposta, sendo uma importante fonte de informação para o monitoramento microbiológico dessas áreas.

Revista Extensão \& Cidadania, v. 9, n. 16, p. 21-32, jul./dez. 2021.

ISSN 2319-0566 DOI: 10.22481/recuesb.v9i16.9828 


\section{Conclusão}

Nestas condições de análises, os resultados demonstraram que 66,7\% das amostras analisadas estavam de acordo com os padrões de potabilidade estabelecidos na legislação. Dos seis fontanários analisados, quatro foram aprovados para consumo, estando as análises em concordância com os parâmetros estabelecidos. Porém, nos fontanários 2 e 5, não são adequados para consumo, pois observou-se valores de $\mathrm{pH}$ acima do indicado. Sugere-se ações de monitoramento continuado e frequente da potabilidade da água para maior segurança dos usuários e, em caso de alterações frequentes, esta será uma importante fonte de informações para ações futuras, apontando a necessidade de medidas corretivas e direcionando ações de educação em saúde da população.

\section{Referências}

ANTUNES, Juliane Macedo; DAHER, Donizete Vago; GIARETTA, Vania Maria Araújo; FERRARI, Maria Fernanda Muniz; POSSO, Maria Belén Salazar. Hydrotherapy and crenotherapy in the treatment of pain: integrative review. Brazilian Journal of Pain, v. 2, p.187-198, 2019.

BARBOSA, Fernanda Elizabeth Sena; GUIMARÃES, Maria Beatriz Lisboa; SANTOS, Carlos Renato Santos; BEZERRA, Adriana Falangola Benjamin; TESSER, Charles Dalcana; SOUSA, Islandia Maria Carvalho. Oferta de práticas integrativas e complementares em saúde na estratégia saúde da família no Brasil. Cadernos de Saúde Pública, v. 36, p. 1-13, 2020.

BRASIL. Reunião da Diretoria Colegiada (RDC) $\mathbf{n}^{\circ}$ 298, de 12 de agosto de 2019. Dispõe sobre a aprovação da Farmacopeia Brasileira, $6^{\text {a }}$ edição. Disponível em: https://www.gov.br/anvisa/pt-br/assuntos/farmacopeia/farmacopeiabrasileira/arquivos/7987json-file-1. Acesso em: 20 mar. 2021.

BRASIL. Ministério da Saúde. Portaria no 2.914, de 12 de dezembro de 2011. Dispõe sobre os procedimentos de controle e de vigilância da qualidade da água para consumo humano e seu padrão de potabilidade. Disponível em:

https://bvsms.saude.gov.br/bvs/saudelegis/gm/2011/prt2914_12_12_2011.html. Acesso em: 20 mar 2021.

BRASIL. Ministério da Saúde. Portaria no 971, de 3 de maio de 2006. Aprova a Política Nacional de Práticas Integrativas e Complementares (PNPIC) no Sistema Único de Saúde. Disponível em:

Revista Extensão \& Cidadania, v. 9, n. 16, p. 21-32, jul./dez. 2021. 
https://bvsms.saude.gov.br/bvs/saudelegis/gm/2006/prt0971_03_05_2006.html. Acesso em: 25 abr. 2021.

BRASIL. Ministério da Saúde. Fundação Nacional de Saúde (FUNASA). Portaria MS no 518, de 25 de maio de 2004. Brasília, DF, 2005. Disponível em:

https://bvsms.saude.gov.br/bvs/publicacoes/portaria_518_2004.pdf. Acesso em: 20 mar 2021.

BROMBERG, M. Safe drinking water: Microbial standards help ensure water quality for consumers. p. 791-798, 1995. Disponível em:

http://www.hermes.ecn.purdue.\%20edu/cgi/convwqtest?/ru-7.il.ascii. Acesso em: 27 abr. 2021.

CAVALCANTE, Rosane Barbosa Lopes. Ocorrência de Escherichia coli em fontes de água e pontos de consumo em uma comunidade rural. Revista Ambiente e Água, v. 9, n. 3, p.150$158,2014$.

DAHI, Eli. Water supply in developing countries: problems and solutions. Lyngby: Eds. Technical, University of Denmark, 1992.

DMAE. Departamento Municipal de Água e Esgoto. Disponível em: http://dmaepc.mg.gov.br/\#. Acesso em: 25 abr. 2021.

DOMINGUES, Vanessa Oliveira; TAVARES, Gilda Dias; STUKER, Fernanda; MICHELOT, Tiago Mozzaquatro; REETZ, Luiz Gustavo Brenner; BERTONCHELI, Claudia Mello; HORNER, Rosmari. Contagem de bactérias heteróficas na água para consumo humano: comparação entre duas metodologias. Revista do Centro de Ciências da Saúde Santa Maria, v. 33, n. 1, p. 15-19, 2007.

GARDA, Gianna Maria. A alteração hidrotermal no contexto da evolução geológica do maciço de Poços de Caldas, MG-SP, 1990. 214 f. Dissertação (Mestrado em Mineralogia e Petrologia) - Instituto de Geociências, Universidade de São Paulo, São Paulo, 1990.

HELLER, Leo. Saneamiento y salud. Washington, D.C.: CEPIS/OPS, 1998.

MARRICHI, Jussara Marques Oliveira. A cidade termal: ciência das águas e sociabilidade moderna entre 1839 a 1931. 2009. 172 f. Dissertação (Mestrado em História) - Instituto de Filosofia e Ciências Humanas, Universidade Estadual de Campinas, Campinas, 2009.

MEGALE, Nilza Botelho. Memórias históricas de Poços de Caldas. 2. ed. Poços de Caldas: Sulminas, 2002.

PAIVA, Roberta Fernanda Paz; SOUZA, Marcela Fernanda Paz. Associação entre condições socioeconômicas, sanitárias e de atenção básica e a morbidade hospitalar por doenças de veiculação hídrica no Brasil. Cadernos de Saúde Pública, v. 34, n. 1, p. 1-11, 2018.

PREFEITURA MUNICIPAL DE POÇOS DE CALDAS. Disponível em: https://pocosdecaldas.mg.gov.br/. Acesso em: 25 abr. 2021.

Revista Extensão \& Cidadania, v. 9, n. 16, p. 21-32, jul./dez. 2021. 
QUINTELA, Maria Manuel. Saberes e práticas termais: uma perspectiva comparada em Portugal (Termas de S. Pedro do Sul) e no Brasil (Caldas da Imperatriz). História, Ciências, Saúde, v. 11, p. 239-260, 2004.

SILVA, Débora Regina Romualdo; MACIEL, Marilene Oliveira Santos; MARTA, Barbara Braga Ferreira; BRONHARO, Tereza Marilene; MICHELIN, Aparecida Fátima. Qualidade da água em escolas públicas municipais: análise microbiológica e teor de nitrato em Araçatuba, estado de São Paulo - Brasil. Revista do Instituto Adolfo Lutz, v.77, 2018.

Recebido: 1.11.2021

Aceito: 28.11 .2021

(9) (-)

This work is licensed under a Creative Commons Attribution 4.0 International License.

Revista Extensão \& Cidadania, v. 9, n. 16, p. 21-32, jul./dez. 2021. 